\title{
Tonal overwriting and inflectional exponence in Amuzgo
}

\author{
Yuni Kim \\ University of Manchester \\ yuni.kim@manchester.ac.uk
}

\section{$\$ 1 \quad$ Introduction}

Amuzgo, an Eastern Oto-Manguean language with close affinities to Mixtecan (Campbell 1997:158), is spoken in the Costa Chica region of Guerrero and Oaxaca States in southern Mexico. This paper deals with the Amuzgo variety of San Pedro Amuzgos, Oaxaca, which has about 4000 speakers and has previously been studied by Smith-Stark and Tapia García (1984, 2002), Tapia García (1999), Stewart \& Stewart (2000), and Buck (2000). The data come from these sources, plus a manuscript by Tapia García (n.d.) containing the full inflectional paradigms of about 1000 words. The data have been partially checked by the author on-site in San Pedro Amuzgos, with Tapia García himself and other native speakers.

In Amuzgo, person inflection in transitive verbs (plus a subset of intransitives) is realized in several simultaneous ways: aside from inflectional affixes, there are stem alternations in tone, vowel height, and/or glottalization. ${ }^{1}$ Because each of the stem-alternation types has multiple possible surface patterns, the intersection and overlaying of these systems on top of each other results in numerous combinations of exponence strategies attested for each cell in the paradigm. The goal of this paper is to describe Amuzgo's tonal morphology and disentangle its role in the inflectional system, focusing on person marking in singular paradigms, where the interplay of lexical and morphological tone with other inflectional structure is especially complex.

Amuzgo tonal inflection is of theoretical interest because there is no inherent relationship between the tonal exponents of inflection and the morphosyntactic features they realize, contra the fairly common assumption that inflectional markers either have unique featural content or are defaults of some kind (see e.g. Müller 2007: 16-17). Instead, in Amuzgo a limited set of tones is used and reused in different paradigm cells, and the set of inflectional classes quite nearly approaches the set of logically possible configurations of these exponents in the paradigm. More concretely, I demonstrate that the sets of inflectional tones for $1^{\text {st }}$ and $2^{\text {nd }}$ person singular forms are coextensive and identical: there are five different tones that are attested as exponents of $1^{\text {st }}$ person, and the same five tones are also the ones attested as $2^{\text {nd }}$ person exponents. Tonal inflectional classes are defined by combinations of $1^{\text {st }}$ and $2^{\text {nd }}$ person tones. In this regard Amuzgo is reminiscent of the Western Nilotic language Nuer (as analyzed by Baerman 2012), whose inflectional classes also exploit the combinatorial possibilities of a small set of elements.

The principal role of tone in the inflectional system is thus not to mark person features as such, but rather to enable lexical retrieval in light of other markers of person category. Listeners can infer person category from affixes and vowel-height/glottalization alternations. However, the lexical identity of the word is obscured by the fact that many stems are segmentally homophonous, and crucial information about lexical tone is not available due to the fact that inflectional tones completely overwrite and replace lexical tones. In order to recover the lexeme behind an inflected verb form, the listener must rely on her inflection-class knowledge of which lexical item carries a particular inflectional tone in the specific paradigm

1 A subset of intransitive verbs inflect for person with a special set of enclitics (see Buck 2000: 376), with no stem alternations at all. 
cell indicated by the less ambiguous exponents of person features; but lexical tone itself is not involved. Arguably, tonal inflection in Amuzgo is a type of inflectional morphology that carries purely morphological information (cf. Aronoff 1994), to the unusually complete exclusion of morphosyntactic information encoded directly as such.

Because this paper is the first attempt in the literature to describe the tonal patterns of Amuzgo person inflection, the bulk of the argumentation is devoted to establishing the relationship between observed tones on inflected forms, and the underlying tonal morphemes that can be considered as the inflectional tones proper. Previous published information on this subject consists only of raw data in the 30 or so sample verb tables in Buck (2000). With the aim of providing both an overview and an analysis, the structure of the paper is as follows: $\S 2$ gives background information on Amuzgo tone, and situates person-marking phenomena within the overall inflectional system. In $\S 3$, I analyze the formal morphological and phonological properties of tonal inflection. Phonologically, I argue that inflectional tones overwrite lexical tones, as opposed to concatenating or fusing with them. I show that inflectional tones cannot be predicted from lexical tones, nor do they have any apparent phonological interactions with them. Morphologically, I demonstrate that the tonal inflection patterns cannot be predicted from a lexical item's other morphophonological properties, such as its membership in other stem-alternation classes; instead, lexemes must be specified for which tonal inflection pattern they take.

Having established the existence of tonal-overwriting inflection as an independent morphological phenomenon, in $\S 4$ we are in a position to ask how many underlyingly distinct tonal inflectional classes Amuzgo has. Although there are no apparent interactions between inflectional tone and lexical tone, surface distinctions can arise from interactions between inflectional tones and their phonological context, without necessarily corresponding to distinct morphological elements. An analysis of the morphological inflection-class inventory requires that we factor out predictable phonological processes. I argue that a phonological process of glottally conditioned tone lowering creates predictably distributed surface allotones in some cases, meaning that two most frequent surface patterns originate from a single default underlying one. Nevertheless, despite the prevalence of the default pattern, many irreducibly distinct inflectional classes remain.

In §5 I summarize the main points, discussing the role of tonal inflection within the overall structure of inflectional exponence, and considering its consequences for further research on Amuzgo morphology as well as for morphological theory in general. In particular, Amuzgo offers a challenge for theoretical proposals that constrain the possible number of inflectional classes in a language based on its inventory of exponents, such as the No-Blur Principle (Carstairs-McCarthy 1994, Cameron-Faulkner and Carstairs McCarthy 2000) and Inflection Class Economy Theorem (Müller 2007).

\section{$\$ 2 \quad$ Amuzgo tones and inflectional categories}

Amuzgo has eight lexically contrastive tones, described in detail by Smith-Stark and Tapia García (1984) and also recognized by Buck (2000). The table in (1) shows the number-based tone labels used by Smith-Stark \& Tapia García (1984) alongside a translation of the Spanish labels in Buck (2000), where H corresponds to alto 'high', M to medio 'medium', and L to bajo 'low'. Two-tone sequences reflect compound tone names; for example bajo-bajo is rendered as LL. In the bottom row of (1), the eight contrastive tones are illustrated with an 8way minimal octuplet. 
(1) Tones of Amuzgo (San Pedro Amuzgos)

\begin{tabular}{|l|c|c|c|c|c|c|c|c|}
\hline SSTG (1984) & $/ 5 /$ & $/ 3 /$ & $/ 34 /$ & $/ 1 /$ & $/ 12 /$ & $/ 35 /$ & $/ 53 /$ & $/ 31 /$ \\
\hline Buck (2000) & $\mathrm{H}$ & $\mathrm{M}$ & $\mathrm{MM}$ & $\mathrm{L}$ & $\mathrm{LL}$ & $\mathrm{MH}$ & $\mathrm{HM}$ & $\mathrm{HL}$ \\
\hline $\begin{array}{l}\text { Minimal } \\
\text { octuplet }\end{array}$ & $\begin{array}{c}\mathrm{n}_{0} \varepsilon^{5} \\
\text { 'dust' }\end{array}$ & $\begin{array}{c}\mathrm{n} \varepsilon^{3} \\
\text { 'cheap' }\end{array}$ & $\begin{array}{c}\mathrm{n} \varepsilon^{34} \\
\text { 'jump.cPL.3sG' }\end{array}$ & $\begin{array}{c}\mathrm{n}_{0} \varepsilon^{1} \\
\text { 'zacate' }\end{array}$ & $\begin{array}{c}\mathrm{n}_{0} \varepsilon^{12} \\
\text { 'monte' }\end{array}$ & $\begin{array}{c}\mathrm{n}_{0} \varepsilon^{35} \\
\text { 'ripe' }\end{array}$ & $\begin{array}{c}\mathrm{n}_{0} \varepsilon^{53} \\
\text { 'sell.cPL.3SG' }\end{array}$ & $\begin{array}{c}\mathrm{n}_{0} \varepsilon^{31} \\
\text { 'already' }\end{array}$ \\
\hline
\end{tabular}

Both systems are phonetic descriptive labels rather than claims about phonological representation, and apart from some minor differences in descriptive detail (comparing e.g. the 31 and HL labels for the same tonal category), they are parallel. Kim's (2011) study of a young speaker suggests intergenerational variation in the phonetic realizations of categories 1 (L), 53 (HM), and 31 (HL), but I will use Smith-Stark \& Tapia García's (1984) tone numbers to refer to the tones, which is the system also used in Tapia García's (n.d.) verb tables.

The possibilities for further reduction are unclear. Although Bauernschmidt (1965) successfully reduced the 11 surface tones of Xochistlahuaca (Guerrero) Amuzgo to 6 underlying ones by arguing for an independent syllable-based parameter of ballisticity, SmithStark and Tapia García (1984) do not find corresponding evidence for the Oaxacan variety of San Pedro Amuzgos. Although Buck's (2000: 372) description splits the 8 tones into "controlled" and "ballistic" ones in a way that implies 5 underlying tones, Kim (2011) uncovers a phonological process that applies to controlled but not ballistic members of the putatively same tonal category, raising problems for the unification of their representations on the tonal tier ${ }^{2}$. We are also aware of no evidence for phonologically contrastive vowel length, despite a cline of durational differences between tone categories (see Kim 2011); we therefore do not follow the Buck (2000) and Stewart \& Stewart (2000) convention of transcribing single versus double vowels.

Tone is one of several elements exploited in Amuzgo for purposes of marking inflectional categories. Others include glottalization and vowel height, plus systems of prefixes, initial consonant mutations (related diachronically if not synchronically to prefixation), and suppletive stem allomorphy. To contextualize the role of tone in the inflectional system, I give a sample paradigm in (2) to illustrate some exponence strategies used in realizing different inflectional categories.

Amuzgo distinguishes singular versus plural number; four basic TAM categories (completive, incompletive, potential, and irrealis); and $1^{\text {st }}, 2^{\text {nd }}$ and $3^{\text {rd }}$ person, plus $1^{\text {st }}$ person inclusive and exclusive. In the following paragraphs I will describe number, TAM, and person marking, in this order.

(2) Inflectional paradigm of $k^{w} h e^{335}$ 'arrive (here)' (Tapia García n.d.: 610)

\begin{tabular}{|c|c|c|c|c|}
\hline & Completive & Incompletive & Potential $^{4}$ & Irrealis \\
\hline $1 \mathrm{sg}$ & thh $\varepsilon^{1}$ & $\mathrm{ma}^{3}-\mathrm{k}^{\mathrm{w}} h \varepsilon^{1}$ & $\mathrm{n}^{5}-\mathrm{nk} \mathrm{k}^{\mathrm{w}} \mathrm{h} \varepsilon^{1}$ & $\mathrm{k}^{\mathrm{w}} \mathrm{h} \varepsilon^{1}$ \\
\hline $2 \mathrm{sg}$ & the? ${ }^{1}$ & $\mathrm{ma}^{3}-\mathrm{k}^{\mathrm{w}} \mathrm{he} ?^{1}$ & $n^{5}-n^{w}{ }^{w} ?^{1}$ & $\mathrm{k}^{\mathrm{w}} \mathrm{he} \mathrm{P}^{1}$ \\
\hline
\end{tabular}

2 This process is a tone-sandhi alternation found in a younger speaker's speech, presumably a recent innovation. Older speakers do not produce this sandhi, and it does not figure in the present data.

3 Although sources on San Pedro Amuzgos Amuzgo use terms that translate to 'past', 'present', 'future', and 'subjunctive', here I use labels that facilitate comparison with other Eastern Oto-Manguean languages. However, the Amuzgo tense-aspect-mood system has not been investigated in depth.

4 The transcriptions here are phonemic; the singular forms are realized with initial velar nasals as a result of assimilation to the following velar plosive. 


\begin{tabular}{|c|c|c|c|c|}
\hline $3 \mathrm{sg}$ & the $?^{35}$ & $P^{5}-k^{w} h e ?^{35}$ & $n^{5}-n k^{w h e} ?^{35}$ & $\mathrm{k}^{\mathrm{w} h e \mathrm{P}^{35}}$ \\
\hline lincl & $\mathrm{sk} \varepsilon^{34}$ & $\mathrm{ko}^{3}-\mathrm{tsk} \varepsilon^{34}$ & $\mathrm{n}^{5}$-tsk $\varepsilon^{34}$ & $\mathrm{ki}^{3}-\mathrm{tsk} \varepsilon^{34}$ \\
\hline $1 \mathrm{excl}$ & $\mathrm{sk}^{31}$ & $\mathrm{ko}^{3}-\mathrm{tsk} \varepsilon^{31}$ & $n^{5}$-tske $\varepsilon^{31}$ & $k i^{3}-t^{2} \varepsilon^{31}$ \\
\hline $2 \mathrm{pl}^{5}$ & $\mathrm{ske}^{3} \mathrm{o} ?^{3}$ & $\mathrm{ko}^{3}-\mathrm{tske}^{3} \mathrm{o} ?^{3}$ & $n^{5}$-ntske ${ }^{3} o ?^{3}$ & $\mathrm{ki}^{3}-\mathrm{tske}^{3} \mathrm{o} ?^{3}$ \\
\hline $3 \mathrm{pl}$ & ske $^{3}$ & $\mathrm{ko}^{3}$-tske ${ }^{3}$ & $n^{5}$-ntske 3 & $k i^{3}-t^{2} k e^{3}$ \\
\hline
\end{tabular}

Despite the size of the paradigm in (2), one characteristic we can note at a very general level is that singular and plural forms are built on different stems. The morphophonological relationship between singular and plural stems for any given lexical item does not appear to be systematically predictable, and in fact the singular and plural stems for the verb in (2) appear to be suppletive, not related by any synchronic phonological processes. Various recurring processes are found, however. According to Buck (2000: 425ff.), plural stems can be derived from singular stems via prefixation of $t$ - or $t^{j}$ - (3ab); instantiate initial-consonant mutation or deletion patterns associated with $t$ - or $t^{j}$ - prefixation $(3 \mathrm{~cd})$; involve no change (3e); move a final glottal stop to prevocalic position (3f); lower a high vowel to high-mid $(3 \mathrm{~g})$; or be suppletive, not being derivable from singular stems by any regular phonological operation (3h). More possible patterns are evident in Tapia García (n.d.).

\begin{tabular}{|c|c|c|}
\hline \multicolumn{3}{|c|}{ Singular versus plural present-tense stems ${ }^{6}$ (selected from Buck 2000: $425 \mathrm{ff}$ ) } \\
\hline Singular & Plural & Gloss \\
\hline$k \tilde{e}^{34}$ & $t-k \tilde{e}{ }^{12}$ & 'summon' \\
\hline Pue $^{1}$ & $\mathrm{t}^{\mathrm{j}}-$ Pue $\mathrm{e}^{3}$ & 'grind' \\
\hline$m \tilde{a}^{1}$ & $t-\tilde{o} \tilde{a}^{3}$ & 'wash' \\
\hline $\mathrm{ke}^{3}$ & $\mathrm{ti}_{-} \mathrm{e}^{3}$ & 'break' \\
\hline $\mathrm{nt} / \mathrm{he}^{3}$ & $\mathrm{nt} / \mathrm{he}^{3}$ & 'push' \\
\hline$n t \int \tilde{o} ?^{34}$ & nt $\int \tilde{o}^{12}$ & 'blink' \\
\hline$n d i^{35}$ & $\mathrm{ndje}^{1}$ & 'hear' \\
\hline tso $^{5}$ & $\mathrm{nda}^{1}$ & 'sleep' \\
\hline
\end{tabular}

Segmental stem changes are not the only possible exponents of plurality. In (2), prefixes $k o^{3}$-and $k i^{3}$ - appear in plural but not singular forms of the present and the subjunctive, respectively. We also observe that singular and plural stems can differ in tone.

The morphological marking of tense, aspect and mood relies (similarly to number marking) on prefixation and/or its diachronic morphophonological heirs, namely mutations and deletions of features in initial consonants. In the paradigm in (2) there are changes at the left-hand side of the stem, ranging from prefixes specific to certain TAM categories, such as $m a^{3}$ - in the present; to changes in initial consonants, namely stem-initial $k^{w}$ - in the present and subjunctive singular versus arguably monosegmental $n k^{w}$ - in future forms; and apparent replacement of initial consonants, where initial $t^{j}$ - in the past singular forms is accompanied by deletion of $k^{w}$ - or $n k^{w}$.

5 The 2pl. enclitic/suffix is included here at least partly to disambiguate 2pl. and 3pl. forms (Tapia García, p.c.), although the $3 \mathrm{sg}$. enclitic $h u^{5}$ and $3 \mathrm{pl} . h o^{5}$, listed in the Buck (2000) paradigms, are absent in Tapia García (n.d.). Since the obligatoriness and syntactic distribution of these morphs is not clear to me, I will not discuss them further, but I note that they are an additional exponent of person and number.

6 In both the singular and the plural, I take third-person forms (minus affixes) as stems, since they are the loci of unpredictability and maximal contrast. The $3 \mathrm{sg}$. is the only cell in the paradigm where any of the 8 tones cna be found, and all plural tones can be predicted on the basis of the $3 \mathrm{pl}$. tone. 
We refer to the tables in Buck (2000: 439) for an extensive classification of initial consonant mutations associated with TAM inflection. Additional aspectual prefixes, not shown here, can also be added to one of the four basic stems to create complex TAM forms such as the past habitual and future habitual forms listed in Tapia García (n.d.). Notably for our purposes here, tone appears to have no role whatsover in TAM inflection: the paradigm in (2) is entirely representative in that tone remains constant across the four forms in each row. Especially important to observe, given that this is an Oto-Manguean language, is that the stability of the stem tone across TAM categories indicates that the Incompletive $m a^{3}$ - and Irrealis $n^{5}$ - prefixes do not trigger any tone sandhi; this is constant across all the data.

In contrast, tone is most active in person marking, which also arguably possesses the most complex combination of exponence strategies. Aside from affixation, person marking involves tone, a system of glottal alternations, and vowel lowering. Regarding affixes, across all TAM categories we find a $2 \mathrm{sg}$. suffix $-?$ (which however is not unambiguously evident in (2), since the singular stem already ends in glottal stop; see $\S 3$ and $\S 4$ for further analysis). In the present tense only, different prefixes group $1 \mathrm{sg}$. and $2 \mathrm{sg}$. $\left(m \mathrm{a}^{3}-\right)$ together to the exclusion of the $3 \mathrm{sg} .\left(?^{5}-\right)$.

Several stem alternations are evident in the $1^{\text {st }}$ person forms in (2). Glottal alternations target $1^{\text {st }}$-person forms: the final glottal stop present in the $2 \mathrm{sg}$. and $3 \mathrm{sg}$. forms is absent from the 1sg. Similary, vowel-height alternations can also be seen: all first-person forms (1sg., 1incl., and 1excl.) feature a low-mid vowel $[\varepsilon]$ as opposed to the high-mid [e] present in other forms. This first-person vowel lowering is exceptionless with high-mid vowels across all verbs, and lexically conditioned in verbs containing high vowels. For this particular verb, $2^{\text {nd }}$ person non-concatenative changes are limited to tone. While the $3 \mathrm{sg}$. forms have tone 35 (rising), both $1^{\text {st }}$ and $2^{\text {nd }}$ person forms alter the tone to 1 (low).

Following this initial look at exponence strategies in Amuzgo inflection, we turn now to a closer examination of the patterns and morphological mechanisms behind various elements of the system, seeking ultimately to characterize the morphological role of tone.

\section{$\S 3 \quad$ Phonological and morphological structure of tonal inflection}

The description of tonal inflection presents two basic analytical problems. First, what is the morphophonological process or operation by which inflectional tones are associated to stems? Second, where in the lexicon or in the grammar do these inflectional tones originate - e.g. as integral elements of memorized stem allomorphs, in lexically arbitrary tonal inflectional classes along the lines of Aronoff (1994), or in regular rules that predictably match verbs with inflectional exponents according to the verb's phonological or morphosyntactic properties? In order to argue for the second possibility - that of inflectional classes - this section will show why neither memorized stem allomorphs nor feature-based rules are appropriate analyses for the generalizations found in the data.

Tonal inflection in singular paradigms displays a wide variety of options. For example, (4) gives the $1 \mathrm{sg}$., $2 \mathrm{sg}$., and $3 \mathrm{sg}$. forms of some verbs of phonotactic shape CV. The first row shows that they all have tone $/ 3 /$ in the $3^{\text {rd }}$ person. However, in $1^{\text {st }}$ and $2^{\text {nd }}$ person singular forms they diverge. In the $1^{\text {st }}$ person, the verbs in (4ab) have tone $/ 53 /$, while $(4 c)$ has tone $/ 3 /$. In the $2^{\text {nd }}$ person, (4ac) both have tone $/ 3 /$, while (4b) is the odd one out with tone $/ 53 /$. While the same two tones are used here, namely $/ 53 /$ and $/ 3 /$, neither is unique to either $1^{\text {st }}$ or $2^{\text {nd }}$ person, and they recombine into three different patterns of $1^{\text {st }}-2^{\text {nd }}$ tonal inflection: the $/ 53 /-/ 3 /$ pattern in (4a), as opposed to /53/-/53/ in (4b), as distinct still from /3/-/3/ in (4c). 
(4) Incompletive singular paradigms for some verbs with $3 \mathrm{sg}$. tone $/ 3 /$

\begin{tabular}{|l|l|l|l|}
\hline & (a) 'sing' & (b) ‘enter' & (c) 'eavesdrop' \\
\hline 3 SG & $P^{5}-\mathrm{ta}^{3}$ & $\mathrm{P}^{5}-\beta \mathrm{a}^{3}$ & $\mathrm{P}^{5}-\mathrm{nda}^{3}$ \\
\hline $1 \mathrm{SG}$ & $\mathrm{ma}^{3}-\mathrm{ta}^{53}$ & $\mathrm{ma}^{3}-\beta \mathrm{a}^{53}$ & $\mathrm{ma}^{3}-\mathrm{nda}^{3}$ \\
\hline $2 \mathrm{SG}$ & $\mathrm{ma}^{3}-\mathrm{ta}-\mathrm{P}^{3}$ & $\mathrm{ma}^{3}-\beta \mathrm{a}-\mathrm{P}^{53}$ & $\mathrm{ma}^{3}-\mathrm{nda}-\mathrm{P}^{3}$ \\
\hline
\end{tabular}

The table in (5) gives the full set of possibilities found in a sample of 133 words culled from Tapia García (n.d.), comprising the majority of paradigms in the list that meet a set of basic criteria for the present study: they are verbal, participate in inflection via stem alternations (as opposed to the enclitics referred to in fn. 1), and are based on monosyllabic stems. Words not meeting these criteria were excluded from the dataset in order to avoid potential effects of tone sandhi or non-verbal inflectional mechanisms. ${ }^{7}$ The table in (5) can be read in the same way as (4): for words with each of the $3 \mathrm{sg}$. tones in the top row (the number of verbs in the sample with that tone being shown below that), all of the attested $1 \mathrm{sg}$. stem tones are listed, followed by all of the attested $2 \mathrm{sg}$. stem tones.

Attested inflectional tones in singular paradigms

\begin{tabular}{|l|l|l|l|l|l|l|l|l|}
\hline $3 \mathrm{SG}$. & $/ 5 /$ & $/ 53 /$ & $/ 31 /$ & $/ 35 /$ & $/ 34 /$ & $/ 3 /$ & $/ 12 /$ & $/ 1 /$ \\
\hline$n=$ & 12 & 5 & 3 & 35 & 12 & 32 & 5 & 29 \\
\hline $1 \mathrm{SG}$. & $/ 53 /, / 3 /, /$ & $/ 53 /$ & $/ 53 /, /$ & $/ 53 /, / 3 /, /$ & $/ 53 /, /$ & $/ 53 /, / 31 /, / 3 /, /$ & $/ 53 /, /$ & $/ 53 /, / 31 /, /$ \\
& $1 /$ & & $3 /$ & $12 /, / 1 /$ & $3 /$ & $1 /$ & $12 /$ & $12 /, / 3 /$ \\
\hline 2 SG. & $/ 53 /, / 31 /, /$ & $/ 53 /, /$ & $/ 31 /$ & $/ 53 /, / 31 /, /$ & $/ 53 /, /$ & $/ 53 /, / 31 /, / 3 /, /$ & $/ 31 /, /$ & $/ 53 /, / 31 /, /$ \\
& $3 /, / 1 /$ & $31 /$ & & $1 /$ & $31 /$ & $12 /, / 1 /$ & $12 /$ & $3 /, / 1 /$ \\
\hline
\end{tabular}

Only five of the eight tones $-/ 53 /, / 31 /, / 12 /, / 1 /$, and $/ 3 /-$ are found in the $1 \mathrm{sg}$. and $2 \mathrm{sg}$., whereas all eight are attested in $3 \mathrm{sg}$. forms; we assume that the $3 \mathrm{sg}$. tone is the lexical tone. While accidental gaps cannot be ruled out in a sample of this size, particularly for less frequent categories, it is already apparent from (5) that inflectional tones is not predictable based on $3^{\text {rd }}$ person (lexical) tone. Each of the inflectional tones - for example tone $/ 53 /$ - is compatible with a wide range of lexical tones, meaning that in at least some forms, lexical tone has left no apparent trace of its identity; and simultaneously, there is no inflectional tone from which a lexical tone can be accurately recovered. These are the hallmarks of tonal overwriting.

Just as the unpredictability of inflectional tones from lexical tones points to a certain phonological analysis of the operations involved, we now show that a lack of robust implicational relationships between tonal inflectional patterns and other stem alternations points to the independent status of tonal inflectional classes in the morphology.

The most prominent type of stem alternations are those involving glottalization. Some

7 For a subset of nouns and property-concept words, possessive or other person-number inflection is very similar to the system described in $§ 2$; there is even apparent compatibility with TAM markers. There are also particle verbs consisting of verb plus e.g. directional particle, where it is the particle (rather than the verb root) that shows stem alternations in person inflection, again in a way similar to $\S 2$. Although it may turn out that the inflectional paradigms under discussion here are used in a uniform way across word classes, I have erred on the side of caution and attempted to control for non-arbitrary morphological factors. 
examples are shown in (6).

(6) Illustrations of stem alternations involving glottalization

\begin{tabular}{|c|c|c|}
\hline & (a) 'arrive', incompletive & (b) 'break', incompletive \\
\hline $1 \mathrm{SG}$ & $\mathrm{ma}^{3}-\mathrm{k}^{\mathrm{w}} \mathrm{h} \varepsilon^{1}$ & $m a^{3}-t^{2} a^{53}$ \\
\hline $2 \mathrm{SG}$ & $\mathrm{ma}^{3}-\mathrm{k}^{\mathrm{w}} \mathrm{he} \mathrm{P}^{1}$ & $m a^{3}-$ tã $^{31}$ \\
\hline $3 \mathrm{SG}$ & $P^{5}-k^{w} h e P^{35}$ & $P^{5}-\mathrm{tã} \mathrm{P}^{31}$ \\
\hline
\end{tabular}

In (6a), a final glottal stop is present in both the $2 \mathrm{sg}$. and $3 \mathrm{sg}$. forms, but absent from the $1 \mathrm{sg}$ form. In contrast, while the paradigm in (6b) also shows final glottal stops in the $2 \mathrm{sg}$. and 3sg., glottalization is still present in the $1 \mathrm{sg}$. form, but appears in a different configuration with respect to the vowel.

Buck (2000: 378ff.) and Stewart \& Stewart (2000) assign verbs to five classes (A, B, $\mathrm{C}, \mathrm{D}$, and $\mathrm{E}$ ) according to the presence and behavior of glottalization in their person-marking paradigms. Classes A and B cover verbs whose third-person forms end in vowels, e.g. shapes $\mathrm{CV}$ and $\mathrm{C}$ ?V. The remaining three classes $(\mathrm{C}, \mathrm{D}$, and $\mathrm{E})$ divide up verbs whose third-person forms end in glottal stop, e.g. of shape CV.$^{8}$ The table in (7) provides a schematic overview of the SIL glottalization classes. Where there is a stem alternation, the minority stem shape is boldfaced. We can see that the alternation in (6a) falls into class E, while the alternation in (6b) is representative of the class $\mathrm{C}$ category.

$\begin{array}{lllll}\text { 3sg. stem } & \text { 1sg. stem } & \text { 2sg. stem } & \text { SIL } & \text { This paper } \\ -\mathrm{V} & -\mathrm{V} & -\mathrm{V} & \mathrm{A} & \text { Non-alternating } \\ -\mathrm{V} P & -\mathrm{V} P & -\mathrm{V} P & \mathrm{D} & \text { Non-alternating } \\ -\mathrm{V} P & -\mathbf{V} & -\mathrm{V} P & \mathrm{C} & 1^{\text {st }} \text { person glottal metathesis } \\ -\mathrm{V} P & -\mathrm{V} & -\mathrm{V} P & \mathrm{E} & 1^{\text {st }} \text { person glottal deletion } \\ -\mathrm{PV} & -\mathrm{V} & -\mathrm{V} & \mathrm{B} & \text { Irregular }\end{array}$

With respect to glottalization alternations in stems, I propose to reanalyze the SIL classification to recognize three groups of verbs: non-alternating, those with $1^{\text {st }}$ person glottal metathesis, and those with $1^{\text {st }}$ person glottal deletion. This schema is simpler than the SIL classification because I have merged the two non-alternating categories (A and D), which do not represent morphologically distinct patterns, and eliminated Class $\mathrm{B}$, which turns out to have only two members after inspection of Stewart and Stewart (2000) and Tapia García (n.d.), and can thus be considered lexically idiosyncratic.

From inspecting the $3 \mathrm{sg}$. forms in (7), we see that stem alternations only occur in verbs ending in lexical glottal stop. Vowel-final verbs, once we eliminate irregular cases, never show glottalization alternations. Class A, illustrated by the present-tense forms in (8), is defined as comprising the verbs of this latter type. Of the 86 vowel-final verbs in the dataset, 84 - i.e. virtually all of them - are non-alternating, falling into Class A. (Suppletive verbs, where alternations in individual features like glottalization cannot be meaningfully observed, are not counted here.)

(8) Vowel-final Class A in Buck (2000) and Stewart \& Stewart (2000)

8 A sixth class (F) is reserved as the dictionary-entry label for the subset of intransitive verbs (regardless of phonotactic shape) that inflect with a separate paradigm of enclitics and are outside the system in $\S 2$. 


\begin{tabular}{|c|c|c|c|c|}
\hline & (a) CV 'burn', incompl. & (b) CV 'burn', cpl. & (c) C?V 'catch', incompl. & (d) CPV 'catch', cpl. \\
\hline $1 \mathrm{sG}$ & $m a^{3}-t s k \rho^{3}$ & $\mathrm{sko}^{3}$ & $m a^{3}-v a^{53}$ & $\mathrm{t}^{2} \mathrm{a}^{53}$ \\
\hline $2 \mathrm{sG}$ & $\mathrm{ma}^{3}$-tsko- $\mathrm{P}^{3}$ & sko-? $?^{3}$ & $m a^{3}-v ? a-?^{3}$ & t?a- $?^{3}$ \\
\hline $3 \mathrm{sG}$ & $P^{5}-$ tsko $^{3}$ & sko $^{3}$ & $2^{5}-\mathrm{vPa}^{3}$ & $\mathrm{tPa}^{3}$ \\
\hline
\end{tabular}

Meanwhile, of the 41 glottal-final (and non-suppletive) verbs in the dataset, 15 (or $37 \%$ of them) are non-alternating ("Class D"). These include both CV? and C?V? shapes, i.e. both those with plain vowels and those with pre-glottalized (or laryngealized) vowels; more specifically, all of the C?V? verbs in the dataset are non-alternating. Some examples of nonalternating, glottal-final singular present-tense paradigms are shown in (9). Interestingly, Tapia García (n.d.) transcribes echo vowels in all first-person forms of verbs in this category. The role of this echo vowel is not known, nor has its distribution been studied; Buck (2000) does not include or mention it. ${ }^{9}$

(9) Glottal-final Non-alternating verbs (Class D)

\begin{tabular}{|c|c|c|c|}
\hline & (a) 'take out' & (b) 'bring a gift' & (c) 'clean' \\
\hline $1 \mathrm{SG}$ & $\mathrm{ma}^{3}-\mathrm{k}^{\mathrm{w}} \mathrm{hi} \mathrm{r}^{53}-\mathrm{i}^{3}$ & $m a^{3}-n d o \rho^{53}-\rho^{3}$ & $m a^{3}-\beta \varepsilon p^{53}-\varepsilon^{3}$ \\
\hline $2 \mathrm{SG}$ & $\mathrm{ma}^{3}-\mathrm{k}^{\mathrm{w}} \mathrm{hi} \mathrm{P}^{1}$ & $\mathrm{ma}^{3}-\mathrm{ndo} \mathrm{P}^{31}$ & $m a^{3}-\beta e 2^{31}$ \\
\hline $3 \mathrm{SG}$ & $?^{5}-\mathrm{kwhi} \mathrm{P}^{3}$ & $P^{5}$-ndo $?^{3}$ & $P^{5}-\beta e P^{1}$ \\
\hline
\end{tabular}

A slightly more common pattern for glottal-stop-final verbs in the dataset is the $1^{\text {st }}$ person Glottal Metathesis alternation ("Class C"). Examples are shown in (10). Overall, 51\% of glottal-final verbs ( 21 of 41$)$ belong to this category. All of them have shape CV? in the $2^{\text {nd }}$ and $3^{\text {rd }}$ person; it perhaps stands to reason that a C?V? verb would not be able to laryngealize an already-laryngealized vowel. The comparisons of different TAM forms for the same verb in (10) illustrate that the presence and location of glottalization in stems remains constant in each person category, across all TAM forms.

(10) Glottal Metathesis stem alternations

\begin{tabular}{|c|c|c|c|}
\hline & (a) 'break', completive & (b) 'break', incompletive & (c) 'break', irrealis \\
\hline $1 \mathrm{sG}$ & t?ã ${ }^{33}$ & $m a^{3}-t 2 a^{53}$ & $n^{5}-t ? a^{53}$ \\
\hline $2 \mathrm{SG}$ & tã $P^{31}$ & $m a^{3}$-tã ${ }^{31}$ & $n^{5}$-tã ${ }^{31}$ \\
\hline $3 \mathrm{SG}$ & tã? ${ }^{31}$ & $P^{5}-\mathrm{tã}^{31}$ & $n^{5}-a_{a} 2^{31}$ \\
\hline
\end{tabular}

It is important to note that "metathesis" is a descriptive cover term referring to alternations in the phonetic and linear position of glottalization, since we do not have phonological arguments for the exact representational difference between pre- and postvocalic glottalization. However, it is useful to keep in mind that prevocalic glottal stops in C?V sequences refer to phonologically laryngealized vowels. Phonetically, the sequences written as C?V are realized with creak and/or glottal stop in the first part of the vowel, giving a CV?V-like, interrupted-vowel type impression. Much as in other Oto-Manguean languages

9 The discovery of the morphological source and identity of these echo vowels may well change the characterization of these verbs as glottally non-alternating. The main point that this is a distinct alternation pattern from the other two possibilities found in glottal-final verbs still stands, however. 
(Silverman 1997), there is a very short (if any) modal phase, followed by creak, followed by a longer modal phase on which tone is realized. Silverman (1997) has convincingly argued that the sequential phasing of nonmodal phonation and tone, found throughout the language family, is an optimal strategy for the phonetic realization of both features on the same vowel. Similarly, orthographic $\mathrm{ChV}$ indicates phonologically breathy-voiced vowels. Here again, the sequencing of breathy and modal phases in the transcription reflects the phonetics, but there is no evidence that these are phonologically distinct segments.

Finally, only a handful of glottal-final verbs -4 of 41 (or about $10 \%$ ) - show the $1^{\text {st }}$ person Glottal Deletion pattern illustrated in (11), where a CV? stem alternates with a $1^{\text {st }}$ person CV stem. Although this alternation seems relatively uncommon in verbs, it appears in the possessive paradigms of at least 7 nouns in Tapia García (n.d.), out of a closed set of kinship, body-part, and other closely-possessed nouns that inflect with §2-like stem changes, indicating that it should probably be considered as a genuine (if minority) class of alternations rather than as a cluster of coincidentally idiosyncratic cases. In both nouns and verbs, the roots belonging to this class are CV?; no words with laryngealized vowels (C?V?) are attested with this pattern.

(11) Glottal Deletion stem alternations (Class E)

\begin{tabular}{|l|l|l}
\hline & (a) 'arrive' & (b) 'receive (gift)' \\
\hline $1 \mathrm{sG}$ & $\mathrm{ma}^{3}-\mathrm{k}^{\mathrm{w}} \mathrm{h} \varepsilon^{1}$ & $\mathrm{ma}^{3}-\mathrm{nda}^{3}$ \\
\hline 2sG & $\mathrm{ma}^{3}-\mathrm{k}^{\mathrm{w} h} \mathrm{P}^{1}$ & $\mathrm{ma}^{3}-\mathrm{nda}^{31}$ \\
\hline $3 \mathrm{sG}$ & $\mathrm{P}^{5}-\mathrm{k}^{\mathrm{w}} \mathrm{he} \mathrm{P}^{35}$ & ? $^{5}-\mathrm{nda}^{34}$ \\
\hline
\end{tabular}

We can now ask whether tonal inflection patterns are in any way parasitic on the threeway distinction in glottalization-based stem allomorphy patterns. The question is relevant for glottal-final verbs, since, as seen in (8), vowel-final verbs are virtually all non-alternating. The table in (12) shows the seven different tonal-inflection patterns for 1sg.-2sg. forms that are attested with verbs ending in a glottal stop. However, the tonal inflection pattern is not predictable based on glottalization class: most tonal patterns are attested with verbs of more than one glottalization type, and the low number of Glottal Deletion verbs in teh sample means that some of the gaps in that row could be accidental. We can conclude that glottalization alternations and tonal alternations in person marking are best seen as two orthogonal classifying systems.

(12) Tonal-inflection pattern and glottalization alternations

\begin{tabular}{|l|c|c|c|c|c|c|l|l|}
$1 \mathrm{sg}$. & $/ 53 /$ & $/ 3 /$ & $/ 31 /$ & $/ 53 /$ & $/ 53 /$ & $/ 3 /$ & $/ 1 /$ & $/ 12 /$ \\
\hline 2 sg. & $/ 31 /$ & $/ 31 /$ & $/ 31 /$ & $/ 1 /$ & $/ 53 /$ & $/ 1 /$ & $/ 1 /$ & $/ 1 /$ \\
\hline Non-alternating & $\mathrm{n}=10$ & $\mathrm{n}=2$ & - & $\mathrm{n}=2$ & - & $\mathrm{n}=1$ & - & - \\
\hline Metathesis & $\mathrm{n}=12$ & $\mathrm{n}=2$ & $\mathrm{n}=1$ & $\mathrm{n}=4$ & $\mathrm{n}=1$ & $\mathrm{n}=1$ & - & $\mathrm{n}=1$ \\
\hline Deletion & - & $\mathrm{n}=1$ & - & - & - & - & $\mathrm{n}=2$ & $\mathrm{n}=1$ \\
\hline
\end{tabular}

Because inflectional tones do not seem to be predictable based on any morphophonological property of verbs, the tones must on some level be idiosyncratically specified. A basic analysis might conceive of inflectional tones as memorized properties of the 
individual allomorphs that are designated to fill particular cells. More abstractly, though, data from irregular verb paradigms suggest that whole tonal inflectional patterns (i.e. 1sg.-2sg. combinations) could be specified at the level of the lexeme. In some irregular verb paradigms, the tonal pattern remains the same across TAM categories despite stem suppletion.

\section{(13) Suppletive paradigms}

a. 'to go'
\begin{tabular}{|l|l|l|l|l|}
\hline & Completive & Incompletive & Potential & Irrealis \\
\hline $1 \mathrm{sG}$ & $\mathrm{t}^{\mathrm{h}} \varepsilon^{1}$ & $\mathrm{~h} 0^{1}$ & $\mathrm{n}^{5}-\mathrm{nk}^{\mathrm{h}} 0^{1}$ & $\mathrm{k}^{\mathrm{h}} 0^{1}$ \\
\hline $2 \mathrm{SG}$ & $\mathrm{t}^{\mathrm{h}} \mathrm{a}^{53}$ & $\beta^{\mathrm{h}} \mathrm{a}^{53}$ & $\mathrm{n}^{5}-\mathrm{nk}^{\mathrm{h}} \mathrm{a}^{53}$ & $\mathrm{k}^{\mathrm{h}} \mathrm{a}^{53}$ \\
\hline $3 \mathrm{SG}$ & $\mathrm{t}^{\mathrm{h}} \mathrm{a}^{1}$ & $\beta^{\mathrm{h}} \mathrm{a}^{5}$ & $\mathrm{n}^{5}-\mathrm{nk}^{\mathrm{h}} \mathrm{a}^{5}$ & $\mathrm{k}^{\mathrm{h}} \mathrm{a}^{5}$ \\
\hline
\end{tabular}

b. 'to break'

\begin{tabular}{|c|c|c|c|c|}
\hline & Completive & Incompletive & Potential & Irrealis \\
\hline $1 \mathrm{SG}$ & t?is ${ }^{53}$ & $\mathrm{ma}^{3}-\mathrm{k} \mathrm{Pio}^{53}$ & $n^{5}-n k \varepsilon^{53}$ & $\mathrm{k} \varepsilon^{53}$ \\
\hline $2 \mathrm{SG}$ & t?io? ${ }^{3}$ & $\mathrm{ma}^{3}-\mathrm{ke} \mathrm{P}^{3}$ & $n^{5}-n k e P^{3}$ & $\operatorname{ke}^{3}$ \\
\hline $3 \mathrm{SG}$ & tPio $^{1}$ & $\mathrm{P}^{5}-\mathrm{k} \mathrm{Pio}^{1}$ & $n^{5}-n k e^{3}$ & $\mathrm{ke}^{3}$ \\
\hline
\end{tabular}

In (13a), the $1 \mathrm{sg}$. past tense form $t^{\text {jh }} \varepsilon^{l}$ 'I went' is built on a different root than the other $1 \mathrm{sg}$. forms (homophonous with the 1sg. past 'I arrived' in (2)), yet the $1^{\text {st }}$ person tone remains consistent across TAM categories. Neither does the different $3 \mathrm{sg}$. tone in the past tense make a difference to the tonal pattern. Similarly, the paradigm for 'to break' in (13b) shows consistent inflectional tones across TAM categories, despite the fact that the paradigm is made up of forms based on two different roots, which furthermore appear to have different lexical tones (tone 1 in the past and present, which are built on $\mathrm{kPio}^{l}$; and tone 3 in the future and subjunctive, built on $k e^{3}$ ). Under a scenario where tones are properties of individual allomorphs, the consistency of inflectional tones across suppletive allomorphs would need to be seen as coincidental, rather than as the logical consequence of an inflectional-class specification militating over all TAM paradigms of the same lexeme.

In sum, the $1^{\text {st }}$ and $2^{\text {nd }}$ person tones of the Amuzgo singular paradigms bear no reliably predictable relationship with either lexical tone or stem allomorphy patterns. This is true both in cases of stem allomorphs that could plausibly be derived by semi-productive but morpholexically specific phonological operations such as Metathesis or Deletion, as well as in cases that are more clearly suppletive. The examples in (13) provide some evidence that inflectional classes may be abstract and lexically diacritic (see e.g. Aronoff 1994), rather than epiphenomena arising from lexical listing of tonally specified stem allomorphs. In terms of implementation, the inflectional tones (in some if not all cases) completely replace lexical tone, being compatible with a wide variety of lexical tones while at the same time not undergoing any apparent phonological changes that are triggered by them.

To contextualize the continued focus on singular paradigms, I note that plural inflectional tones - unlike the singular ones - are fully predictable. The rules for plural tones are illustrated in (14), based on Buck (2000: 386). Both total overwriting and lexical-tone manipulation are evident. While the $2 \mathrm{pl}$. and $3 \mathrm{pl}$. forms always carry the same tone, which may be considered the lexical tone and can be any of the 8 phonologically contrastive ones, 
the $1^{\text {st }}$ person exclusive always takes tone $/ 31 /$, which simply displaces the lexical tone without being affected by it. This is analyzable as a $/ 31 /$ tonal morpheme, carrying $1{ }^{\text {st }}$ person exclusive features, which overwrites lexical tone.

$$
\text { Inflectional tones in plural paradigms }
$$

\begin{tabular}{|l|l|l|l|l|l|l|l|l|}
\hline 1 INCL. & $/ 5 /$ & $/ 53 /$ & $/ 31 /$ & $/ 35 /$ & $/ 34 /$ & $/ 34 /$ & $/ 12 /$ & $/ \mathbf{1 2} /$ \\
\hline 1 EXCL. & $/ 31 /$ & $/ 31 /$ & $/ 31 /$ & $/ 31 /$ & $/ 31 /$ & $/ 31 /$ & $/ 31 /$ & $/ 31 /$ \\
\hline 2 PL. & $/ 5 /$ & $/ 53 /$ & $/ 31 /$ & $/ 35 /$ & $/ 34 /$ & $/ 3 /$ & $/ 12 /$ & $/ 1 /$ \\
\hline 3 PL. & $/ 5 /$ & $/ 53 /$ & $/ 31 /$ & $/ 35 /$ & $/ 34 /$ & $/ 3 /$ & $/ 12 /$ & $/ 1 /$ \\
\hline
\end{tabular}

For six of the eight lexical tones, the tone for $1^{\text {st }}$ person inclusive forms remains unchanged. The other two $-/ 3 /$ and $/ 1 /$ - are changed $/ 34 /$ and $/ 12 /$, respectively. The fact that the mid tone stays in the mid range, and the low one in the low range, plus the fact that they undergo a similar kind of transformation (i.e. addition of a slight rising contour), points to both lexical tones being operated on by the same process. While Buck (2000: 386) suggests that this process is one of converting ballistic tones to controlled ones, I will refrain from speculating on the representational parameters involved, pending further investigation of the tonal phonology. It is also not clear whether the rule for $1^{\text {st }}$ person inclusive operates on all forms, but for principled reasons applies vacuously to most tonal categories, or whether the process is specifically restricted to lexical tones $/ 3 /$ and $/ 1 /$. Either way, the inflectional tones in plural paradigms are completely predictable based on a combination of 1 st-exclusive overwriting and lexical tone, and there is only one set of patterns: no inflectional-class distinction need be invoked.

\section{$\S 4 \quad$ From surface patterns to inflectional classes}

In this section I take a closer look at the inventory of tonal person-marking patterns found in the singular paradigms of 133 morphologically simplex verbs. The main issue of this section is to establish how many morphological patterns of tonal inflection are found in Amuzgo singular paradigms. The surface-distinct patterns discussed in $\S 3$ may not always reflect morphologically distinct patterns, since varying surface forms could be produced by interactions between lexical or morphological tones, as Williams (2005) proposes for nominal inflection in the Xochistlahuaca (Guerrero) variety of Amuzgo. Although we saw in $\S 2$ that there are no sandhi processes evident between lexical and inflectional tones, here I show that there is a tone-altering interaction between morphological tones and a different phonological property of stems, namely final glottal stops.

Key observations include the emergence of very common patterns alongside much rarer ones; and the complementary distribution of patterns which appear either only on stems ending in a glottal stop, or not ending in a glottal stop, but not both. Positing a process of glottally-conditioned tone lowering allows us to unify some of the surface-distinct apparent inflectional classes into a smaller number of morphologically genuine ones. The formulation of this process points to certain phonological representations for Amuzgo tones, which have previously been studied primarily from a phonetic point of view (Smith-Stark \& Tapia García 1984, Kim 2011; though see Bauernschmidt 1965 and Williams 2005 on the Amuzgo variety of Xochistlahuaca, Guerrero).

In the previous section, the table in (12) illustrated the seven different combinations of 
1sg.-2sg. inflectional tones that are found on glottal-final verbs. When vowel-final verbs are included, the number of patterns rises to 15 . The coincidentally numbered table in (15) shows all the attested combinations of $1 \mathrm{sg}$. and $2 \mathrm{sg}$. tones, along with the numbers of vowel-final and glottal-final verbs displaying each pattern.

Surface patterns of tonal inflection

\begin{tabular}{|l|r|r|r|r|r|r|r|r|r|r|r|r|r|r|r|}
\hline & \multicolumn{4}{|c|}{ Patterns on V-final verbs } & \multicolumn{4}{|c|}{ Patterns on ?-final verbs/Both } \\
\hline Class & \multicolumn{1}{|c|}{$\mathrm{A}$} & $\mathrm{B}$ & $\mathrm{C}$ & $\mathrm{D}$ & $\mathrm{E}$ & $\mathrm{F}$ & $\mathrm{G}$ & $\mathrm{H}$ & $\mathrm{I}$ & $\mathrm{J}$ & $\mathrm{K}$ & $\mathrm{L}$ & $\mathrm{M}$ & $\mathrm{N}$ & $\mathrm{O}$ \\
\hline 1sg. & $/ 53 /$ & $/ 53 /$ & $/ 53 /$ & $/ 31 /$ & $/ 3 /$ & $/ 12 /$ & $/ 1 /$ & $/ 1 /$ & $/ 53 /$ & $/ 53 /$ & $/ 3 /$ & $/ 12 /$ & $/ 31 /$ & $/ 3 /$ & $/ 1 /$ \\
\hline 2sg. & $/ 53 /$ & $/ 3 /$ & $/ 12 /$ & $/ 1 /$ & $/ 3 /$ & $/ 12 /$ & $/ 53 /$ & $/ 3 /$ & $/ \mathbf{3 1} /$ & $/ \mathbf{1} /$ & $/ \mathbf{3 1} /$ & $/ \mathbf{1} /$ & $\mathbf{3 1} /$ & $/ \mathbf{1} /$ & $/ \mathbf{1} /$ \\
\hline $\mathrm{V \#}$ & 43 & 21 & 1 & 8 & 2 & 2 & 4 & 1 & - & 1 & 1 & - & - & 2 & - \\
\hline P\# & 1 & - & - & - & - & - & - & - & 22 & 6 & 5 & 2 & 1 & 2 & 2 \\
\hline
\end{tabular}

Crucial to observe here is that all five inflectional tones can appear in either $1^{\text {st }}$ or $2^{\text {nd }}$ person. Difference between patterns consist of varying distributions of this common pool of elements between the two cells. In the sample, 15 of the 25 logically possible combinations are attested.

Another feature of the table in (15) is that there are salient asymmetries in the number of verbs displaying each tonal inflection pattern. Amuzgo has three patterns that clearly predominate over the others in terms of members: Class A /53/-/53/ (on 44 verbs), Class B / $53 /-/ 3 /$ (on 21 verbs), and Class I /53/-/31/ (on 22 verbs). None of the other patterns is shown by more than 8 verbs in the sample. This is unlike the Western Nilotic language Dinka, which despite being similar in that it recombines a small set of exponents to create different inflectional classes, is argued by Ladd, Remijsen \& Manyang (2009) to lack any default or regular inflectional pattern.

A third striking pattern that emerges is that most tonal inflection patterns are exclusive or nearly exclusive either to vowel-final verbs or glottal-final verbs; just a few patterns are attested on both. Once the vowel-final patterns are isolated, we see a generalization in the $2 \mathrm{sg}$. tones: glottal-final verbs can only ever take a tone ending in /1/ (low falling or low level) for this person category. These two facts can be connected: the complementary distribution of tonal inflection patterns with respect to phonological environment suggests a phonological process deriving surface-distinct patterns from common underlying forms, and the restriction on $2 \mathrm{sg}$. tones for glottal-final verbs suggests that this phonological process may be a tonelowering one that is responsible for the consistent output of tones ending at a low level.

The morphophonological structure of the $2 \mathrm{sg}$. forms of glottal-final verbs provides a context whose uniqueness accounts for why a phonological process would apply in these forms to the exclusion of others. While they give the auditory impression of ending in a single glottal stop, there are two possible sources for it: either the lexical final glottal stop of the verb, or the 2 sg. suffix - ?.

(16) Ambiguous morphological affiliation of final [?] in 2sg. of CV? verbs

\begin{tabular}{|l|l|l}
\hline & (a) 'enter', present & (b) 'summon', present \\
\hline 1 sG & $\mathrm{ma}^{3}-\mathrm{va}^{53}$ & $\mathrm{ma}^{3}-\mathrm{k} \tilde{\varepsilon}^{53}$ \\
\hline
\end{tabular}




\begin{tabular}{|l|l|l}
\hline 2sG & $\mathrm{ma}^{3}-\mathrm{va}-\mathrm{P}^{53}$ & $\mathrm{ma}^{3}-\mathrm{kẽ} \mathrm{P}^{31} \mathrm{OR} \mathrm{ma}^{3}-\mathrm{ke}-\mathrm{P}^{31}$ \\
\hline 3sG & $\mathrm{P}^{5}-\mathrm{va}^{3}$ & $\mathrm{P}^{5}-\mathrm{ke \tilde {P }}{ }^{34}$ \\
\hline
\end{tabular}

In the 2 sg. forms of vowel-final verbs like in (16a) we see the suffix unambiguously, but in (16b) it is unclear where to put the morpheme boundaries, i.e. which of the competing glottal stops has surfaced, or if there is even a way in which the single glottal stop somehow corresponds simultaneously to the underlying material or both stems and affixes. It is not within the scope of this paper to fully resolve the segmentation ambiguity, so I will call this a "double glottalization" context while remaining agnostic about the morphophonological representation of the actual output.

My proposal is that the two largest tonal-inflection patterns, Class A /53/-/53/ and Class I /53/-/31/, reduce to a single underlying one, /53/-/53/, once we posit a process of midto-low tone lowering ( $3-->1)$ in the double-glottalization context. I have abstractly indicated this context as CVP? in (17). This unified inflectional class is now by far the largest of the tone patterns, accounting for about $50 \%$ of the verbs in the dataset, and can be considered the default.

\section{Tone Lowering}

$\begin{array}{ll}\text { a. } & / 3 /-->[1] / \text { CV?? } \\ \text { b. } & /(5) 3 /-->[(5) 1] / \text { CV?? }\end{array}$

The formulation of the rule as in (17a), targeting only the second element in the underlying /53/ contour, is motivated in two ways. First, a process of $/ 3 /->/ 1 /$ tone lowering in glottalization contexts also appears on prefix allomorphs that alternate (for poorly understood reasons) between CV and CV? shapes.

\section{Tone Lowering in Prefixes: 3 --> 1 alternation}

\begin{tabular}{|c|c|c|c|c|}
\hline & (a) 'walk', past sg. & (b) 'walk', pres. sg. & (c) 'float', pres. sg. & (d) 'float', pres. pl. \\
\hline $1 \mathrm{st}$ & $\mathbf{t}^{\mathrm{j}} \mathbf{e} \mathbf{P}^{1}-\mathrm{ka}^{1}$ & $\boldsymbol{\beta a}^{1}{ }^{1}-\mathrm{ka}^{1}$ & $m a^{3}-n t^{j h} a^{53}$ & $\mathbf{m a} \mathbf{P}^{1}-\mathrm{nt}^{\mathrm{jh}} \mathrm{a}^{12}$ \\
\hline 2nd & $\mathrm{ta}^{3}-\mathrm{ka}-?^{1}$ & $\beta a^{3}-k a-?^{1}$ & $m a^{3}-n \mathrm{tin}^{\mathrm{h}} \mathrm{a}-\mathrm{P}^{3}$ & $\mathbf{m a} \mathbf{P}^{1}-\mathrm{nt}^{\mathrm{jh}} \mathrm{a}^{1}-\mathrm{o} \mathbf{P}^{3}$ \\
\hline $3 \mathrm{rd}$ & $\operatorname{ta}^{1}-\mathrm{ka}^{5}$ & $\beta a^{5}-k a^{5}$ & $m a^{3}-n t^{\text {th }} a^{3}$ & $\mathbf{m a} ?^{1}-n t^{\mathrm{jh}} \mathrm{a}^{1}$ \\
\hline
\end{tabular}

In (18a) and (18b), we see that the glottal-final prefix allomorphs $t^{j} e^{P^{l}-}, t a ?^{l}-$, and $\beta a ?^{l}$ all have tone 1, while the vowel-final ones $t a^{3}$ - and $\beta a$ - have tone 3 or 5 . Another set of prefix alternations is evident when comparing singular (18c) and plural (18d) forms of the verb 'to float', which is one of a set of verbs showing this same alternation. The prefix on singular forms is $m a^{3}$-, with tone 3 on a CV syllable, but the plural allomorph is $m a ?^{2}$-, with a lowered tone 1 on a CV? syllable. While these phonological environments are not completely parallel to the putative CV?? context, the similarity suggests that further analysis of Amuzgo morphophonological structure may be able to unify the two processes.

The other motivation for the formulation of Tone Lowering as in (17a) is to enable Tone Lowering, whose trigger is at the right edge of the syllable, to operate locally and affect the final half of the contour, to the extent that there is no need for a phonologically global lowering of the entire tone. In fact, there is some independent evidence from tone in Spanish 
loanwords that the correct phonological representation of tone $/ 31$ / is $\mathrm{HL}$, rather than $\mathrm{ML}$ as implied by the tone numbers.

(19) Tone in Spanish loans

\section{Oxytone}

a. $\quad \mathrm{su}^{31}$ 'blue' $(<a z u l)$

b. $\quad \mathrm{a}^{3} \mathrm{bri}^{31}$ 'April' $(<$ abril $)$

c. $\quad$ ta $^{3}$ ria $^{31}$ 'homework' $(<$ tarea $)$
Paroxytone

d. $\quad \mathrm{ka}^{5} \mathrm{le}^{1} \quad$ 'mayor' $(<$ alcalde $)$

e. $\quad$ ba $^{3} \mathrm{rre}^{5} \mathrm{ta}^{1} \quad$ 'crowbar' $(<$ barreta $)$

f. ska $^{3} \mathrm{le}^{5} \mathrm{ra}^{1} \quad$ 'ladder' $(<$ escalera $)$

The majority of loanwords with final stress (19a-c) have tone "31" on the stressed syllable, whereas paroxytones (19d-f) have a 5-1 tone pattern spread across the two final syllables. These patterns can be unified if we revise the representation of tone $/ 31 /$ to $/ 51 /$ : we now have an identical melody consisting of $5(\mathrm{H})$ and $1(\mathrm{~L})$, which are simply associated differently to words of different prosodic shapes.

Therefore, if Tone Lowering affects only the second half of the contour to change /53/ to [51], as illustrated in (17b), then the pared-down rule gives us a more correct output representation - in addition to potentially being more generally applicable to morphophonological phenomena outside the $2 \mathrm{sg}$. forms of glottal-final verbs, such as the prefixes in (18). It is nevertheless important to note the morphological specificity of tonal lowering, since tones $/ 1 /$ and $/ 51 /$ do freely occur on vowel-final (e.g. CV) syllables elsewhere, just as tones $/ 3 /$ and $/ 53 /$ freely occur on glottal-final (e.g. CV?) syllables. On the other hand, the postulation of Tone Lowering creates an ambiguity in classes $\mathrm{K} / 3 /-/ 51 /$ and $\mathrm{M} / 51 /-/ 51 /$, found on stems ending in a glottal stop, where the second-person form surfaces with tone $/ 51 /$. In the absence of morphological alternations, we do not know whether this tone $/ 51 /$ reflects an underlying, unchanged $/ 51$, or whether it has been produced by Tone Lowering from underlying /53/.

The Tone Lowering process in (17), and its success in enabling the identification of a default /53/-/53/ inflectional class that encompasses surface classes A and I, raises the possibility of further collapsing surface tonal-inflection patterns according to their complementary distribution on vowel-final and glottal-final syllables. From the table in (13), another pair of candidates that reduce to a single category is Class B /53/-/3/, a frequent pattern limited to $\mathrm{V}$-final verbs, and Class $\mathrm{J} / 53 /-/ 1 /$, a pattern attested on six ?-final verbs in the dataset and one V-final verb. If the V-final verb is dealt with separately, perhaps as a lexical exception and not a true member of the same inflectional class, Tone Lowering gets us the complementary distribution for free.

The paradigms in (20) show V-final and ?-final examples of verbs in the inflectional class that has underlying tones $/ 53 /-/ 3 /$. In the $2 \mathrm{sg}$. form of 'eat', Tone Lowering applies to turn underlying $/ 3 /$ into surface tone $/ 1 /$.

Proposed /53/-/3/ class: V-final and P-final examples

\begin{tabular}{|l|l|l}
\hline & (a) ‘sing', present & (b) 'eat', present \\
\hline $1 \mathrm{SG}$ & $\mathrm{ma}^{3}-\mathrm{ta}^{53}$ & $\mathrm{ma}^{3}-\mathrm{k}^{\mathrm{w}} \mathrm{Pa}^{53}$ \\
\hline 2SG & $\mathrm{ma}^{3}-\mathrm{ta}-\mathrm{P}^{3}$ & $\mathrm{ma}^{3}-\mathbf{k}^{\mathrm{w}} \mathrm{a}(\mathbf{2}-) \mathbf{P}^{1} \quad / 3 /-->[1]$ \\
\hline $3 \mathrm{SG}$ & $\mathrm{P}^{5}-\mathrm{ta}^{3}$ & $\mathrm{P}^{5}-\mathrm{k}^{\mathrm{w}} \mathrm{a} \mathbf{P}^{3}$ \\
\hline
\end{tabular}


Beyond this, it is not clear how many more surface patterns can be unified, or indeed if it is desirable to consider infrequent patterns as morphologically semiproductive rather than irregular. The infrequent Class $\mathrm{H} / 1 /-/ 3 /$, found on a single $\mathrm{V}$-final verb (plus in a suppletive paradigm, not counted, where the lexically final segment cannot be assessed), can in principle be merged with Class $\mathrm{O} / 1 /-/ 1 /$, found on two glottal-final verbs, with no extra stipulation. It is also possible that Tone Lowering should be extended to $/ 12 /$, converting it into tone $/ 1 /$ by lowering the second half of the contour, despite the fact that this tone does not rise phonetically to a mid level. This would achieve a further reduction of the $\mathrm{V}$-final Class $\mathrm{F}$ pattern /12/-/12/ and P-final Class L pattern /12/-/1/ into underlying /12/-/12/. More evidence, including an expansion of the scope of analysis to morphologically derived verbs, may shed light on these particular patterns, and on the extent to which they are systematically restricted to V-final and ?-final contexts beyond the controlled, morphologically homogeneous sample inspected for the current study.

Already, though, four of the most frequent tonal inflectional patterns have been reduced to two main inflectional classes that cover the majority of verbs in the dataset. A revision of the tonal-pattern chart in terms of inflectional classes (and corrected tonal representations) is presented in (21). The unified classes as proposed in this section have been boldfaced.

Inflectional classes

\begin{tabular}{|c|c|c|c|c|c|c|c|c|c|c|c|}
\hline \begin{tabular}{|l} 
Clas \\
s
\end{tabular} & $\mathbf{A} / \mathbf{I}$ & $\mathbf{B} / \mathbf{J}$ & $\mathrm{C}$ & $\mathrm{D}$ & $\mathrm{E}$ & $\mathbf{F} / \mathbf{L}$ & $\mathrm{G}$ & H/O & $\mathrm{K}$ & $\mathrm{M}$ & $\mathrm{N}$ \\
\hline $1 \mathrm{sg}$. & 53 & 53 & 53 & 51 & 3 & 12 & 1 & 1 & 3 & 51 & 3 \\
\hline 2 sg. & 53 & 3 & 12 & 1 & 3 & 12 & 53 & 3 & 51 & 51 & 1 \\
\hline$V \#$ & 43 & 21 & 1 & 8 & 2 & 2 & 4 & 1 & 1 & 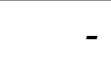 & 2 \\
\hline ?\# & $22^{10}$ & 6 & - & - & - & 2 & - & 2 & 5 & 1 & 2 \\
\hline
\end{tabular}

Overall, the resulting picture is mixed: while the majority of verbs are now classifiable in terms of a major inflectional class, there remains a residue of smaller classes whose internal structure and relationships are less apparent. While further analysis may be able to unify more surface patterns into underlying inflectional classes, and evidence may be found for considering some of the infrequent patterns to be irregular, but for now there is a stubborn array of tonal inflectional patterns that persist in creating an inflectional-class system that has a nontrivial degree of complexity and arbitrariness alongside the order and predictability of the default pattern(s).

\section{$\S 5 \quad$ Conclusion}

We have seen that the tonal inflectional classes of Amuzgo exploit the combinatorial possibilities of a small set of elements, similarly to the Western Nilotic language Nuer (as analyzed by Baerman 2012). Such languages appear to contradict principles in the theoretical morphology literature that posit restrictions on the number of inflectional classes that can

10 This number does not include the exceptional glottal-final verb having a $2 \mathrm{sg}$. form with [53], since the logic of Tone Lowering would require this verb to be irregular, i.e. outside the inflectional-class system. Similar logic applies in the $\mathrm{V} \#$ cell of the next category. 
exist within an inflectional system, given the markers that are available. For example, the Paradigm Economy Principle (Carstairs 1987), given in (22), states that the number of inflectional classes for a paradigm cannot exceed the greatest number of possible exponents for a single cell.

\section{Paradigm Economy Principle (Carstairs 1987: 51)}

"When in a given language $\mathrm{L}$ more than one inflectional realization is available for some bundle or bundles of non-lexically-determined morphosyntactic properties associated with some part of speech $\mathrm{N}$, the number of macro-paradigms for $\mathrm{N}$ is no greater than the number of distinct 'rival' macroinflections available for that bundle which is most generously endowed with such rival realizations."

In Amuzgo there are five possible inflectional tones for 1sg. forms, and a minimum of four for $2 \mathrm{sg}$. forms (due to the surface neutralization of $/ 53 /$ and /51/). The Paradigm Economy Principle predicts that there should be no more than five distinct paradigms, a prediction that is falsified by the 11 inflectional classes listed in table (21). Although deeper analysis of these surface patterns may be possible, the task of eliminating six classes would not appear to be a trivial one.

The subsequent and related No Blur Principle (Carstairs-McCarthy 1994, CameronFaulkner \& Carstairs-McCarthy 2000) proposes that at most one allomorph - for our purposes here, at most one inflectional tone - can fail to predict the rest of the paradigm.

\section{No-Blur Principle (Carstairs-McCarthy 1994: 742)}

"Within any set of competing inflectional realizations for the same paradigmatic cell, no more than one can fail to identify inflection class unambiguously."

In the case of Amuzgo, four of the five 1sg. tones should correspond unambiguously to specific 2sg. tones. Nevertheless, even the reduced table in (21) does not conform to this hypothesis. Among the $1 \mathrm{sg}$. tones, only tone $/ 12 /$ unambiguously tells us the $2 \mathrm{sg}$. tone, which is also tone /12/; the other four all have multiple possibilities for what the $2 \mathrm{sg}$. tone can be. Looking at the $2 \mathrm{sg}$. cell makes matters worse worse: all of the $2^{\text {nd }}$ person tones are attested with multiple $1^{\text {st }}$ person tones.

As a final example, the Inflection Class Economy Theorem of Müller (2007) is given in (24).

Inflection Class Economy Theorem (Müller 2007: 164):

"Given a set of $n$ inflection markers, there can be at most $2^{\mathrm{n}-1}$ inflection classes, independently of the number of grammatical categories that the markers have to distribute over."

A maximum of $2^{n-1}$ classes where $n=5$, as it does in Amuzgo, yields a limit of 16 classes for the five markers. Amuzgo does fall within this, according to the data and analysis presented here. However, the theorem is based on what Müller (2007: 16) calls the Syncretism Principle: "For each marker, there is a unique specification of morphosyntactic features." The Amuzgo data clearly do not bear out this assumption. It may be that the number of inflectional classes has been limited by the fact that the paradigms under discussion have involved an 
extremely limited number of cells - just two - while the data are, in other ways, not in line with the spirit of the theory.

The Syncretism Principle captures the fundamental incompatibility between Amuzgo inflection and the well-known proposals in (22)-(24): the idea that inflectional elements are direct exponents of morphosyntactic features - direct in the sense that morphosyntactic features should be recoverable from the inflectional element alone, without necessary reference to other exponents of the same category or other properties of the word. Even in cases of syncretism, it is usually the case that the choice of exponent at least narrows down the range of morphosyntactic features that could possibly be interpreted from it. In Amuzgo this is only true in a probabilistic or statistical sense: after undoing the effects of phonology, recovery of an underlying /53/ inflectional tone may influence the listener decide between $1^{\text {st }}$ and $2^{\text {nd }}$ person based on frequency bias, but in principle the tone itself cannot tell us which of the cells in this two-cell paradigm a form is located in.

The listener can only infer person category from other, more direct clues such as the 2 sg. suffix $-?$ or the fact that a $1^{\text {st }}$ person stem can never have a high-mid vowel (it always lowers to low-mid). Similar ambiguities obtain with each of the other inflectional tones. What is the role of tonal inflection in Amuzgo, then, if tonal morphs have no restrictions on the morphosyntactic features they can carry? The tonal-overwriting mechanism also means that inflectional tones obliterate, rather than preserve, information about lexical tones; so overall they appear to carry neither lexical nor grammatical information.

Instead, tonal exponents are only meaningful in relation to the other components of the inflectional system. The inflectional role of tone in Amuzgo, and probably elsewhere in OtoManguean, seems to be to carry purely morphological information - i.e. about inflectional class - that indirectly enables the listener to recover the intended lexical item through knowledge about the indexation of verbs to specific inflectional classes.

\section{Tonal inflection and lexical recovery}

\begin{tabular}{|c|c|c|c|}
\hline & (a) 'inhale', present & (b) 'vomit', present & (c) 'break', present \\
\hline $1 \mathrm{sG}$ & $m a^{3}-t^{53}$ & $m a^{3}-t^{53}$ & $m a^{3}-t ? a^{53}$ \\
\hline $2 \mathrm{SG}$ & $m a^{3}-t a ̃-?^{53}$ & $m a^{3}-t a ̃-?^{3}$ & $m a^{3}-\operatorname{tã}\left(P_{-}\right) ?^{51}$ \\
\hline $3 \mathrm{SG}$ & $P^{5}-\mathrm{ta}^{34}$ & $P^{5}-\tilde{a}^{3}$ & $P^{5}$-tã $2^{51}$ \\
\hline
\end{tabular}

In the 2 sg. form $m a^{3}-t \tilde{a}-P^{53}$ in (25a), the inflectional tone $/ 53 /$ by itself does not disambiguate person category. Taking into account the relationship between the inflectional tone and the final glottal stop, however, the form is identifiable as $2 \mathrm{sg}$.: it carries the $2 \mathrm{sg}$. glottal suffix, and we know that this glottal stop is not a lexical one because the tone has surfaced as $/ 53 /$ rather than undergoing Tone Lowering. If it had undergone Tone Lowering to $/ 51 /$, the word would be interpretable as the $2 \mathrm{sg}$. form of 'break' in $(25 \mathrm{c})$. The fact that this word has tone $/ 53 /$ in the $2^{\text {nd }}$ person, in turn, means that it can only be 'inhale' - since 'inhale' is the verb with root segmental content $t \tilde{a}$ that belongs to an inflectional class that takes /53/ in the $2^{\text {nd }}$ person. Meanwhile, similar logic applies to 'vomit' in (25b): although the $1 \mathrm{sg}$. form is actually homophonous with the $1 \mathrm{sg}$. of 'inhale', it is the conjunction of tone $/ 3 /$ and final glottal stop that help to identify it as the $2 \mathrm{sg}$. of this particular lexical item - despite the fact that the tone itself carries neither lexical nor morphosyntactic information, but rather functions in a highly paradigmatic way to ultimately be effective in conveying both.

In sum, it has been necessary to disentangle the various arenas where tone operates 
within Amuzgo morphophonology - tone from other stem alternations, lexical from inflectional tones, underlying tones from surface ones - to arrive at an object of morphological analysis, which has been an apparent system of tonal inflectional classes that is independent from other inflectional stem alternations. It is independent, however, only in the sense of being arbitrarily specified. Precisely because of its abstract morphological status, the function and interpretation of Amuzgo tone relies so heavily on interaction with other inflectional exponents that it challenges the typological picture of what a possible system of inflectional morphology looks like.

\section{Acknowledgements}

I would like to express my gratitude to Oralia Tapia Cruz, Fermín Tapia García, and their families, for their friendship, support, and sharing of expertise in my fledgling studies of their language. In particular, Don Fermín has generously shared with me his as-yet unpublished verb tables, on which much of this analysis is based. I would like to thank the editors and the audience at the Tons et Paradigmes workshop in Paris for their valuable feedback. The fieldwork was sponsored by an LLC School Research Support Fund grant from the University of Manchester.

\section{References}

Aronoff, Mark. 1994. Morphology by itself: Stems and inflectional classes. Cambridge, MA: MIT Press.

Baerman, Matthew. 2012. Paradigmatic chaos in Nuer. Language 88(3): 467-494.

Baerman, Matthew \& Greville G. Corbett. 2012. Stem alternations and multiple exponence. Word Structure 5(1): 52-68.

Bauernschmidt, Amy. 1965. Amuzgo syllable dynamics. Language 41: 471-483.

Buck, Marjorie. 2000. Gramática amuzga de San Pedro Amuzgos, Oaxaca. In C. Stewart \& R. Stewart, Diccionario amuzgo de San Pedro Amuzgos, Oaxaca, 361-480.

Campbell, Lyle. 1997. American Indian languages: the historical linguistics of Native America. Oxford: OUP.

Cameron-Faulkner, Thea and Andrew Carstairs-McCarthy. 2000. Stem alternants as morphological signata: evidence from blur avoidance in Polish nouns. Natural Language and Linguistic Theory 18: 813-835.

Carstairs, Andrew. 1987. Allomorphy in Inflexion. London: Croom Helm.

Carstairs-McCarthy, Andrew. 1994. Inflection classes, gender, and the principle of contrast. Language 70: 737-787.

Kim, Yuni. 2011. Algunas evidencias sobre representaciones tonales en amuzgo de San Pedro Amuzgos. Proceedings of CILLA V (http://www.ailla.utexas.org/site/cilla5/Kim_CILLA_V.pdf). Austin: University of Texas.

Ladd, D. Robert, Bert Remijsen, \& Caguor Adong Manyang. 2009. On the distinction between regular and irregular inflectional morphology: evidence from Dinka. Language 85(3): 659-670.

Müller, Gereon. 2007. Notes on paradigm economy. Morphology 17: 1-38.

Silverman, Daniel. 1997. Laryngeal complexity in Otomanguean vowels. Phonology 14: 235261. 
Smith-Stark, Thomas and Fermín Librado Tapia García. 1984. Los tonos del amuzgo de San Pedro Amuzgos. Anales de Antropología 21(1): 199-220.

Smith-Stark, Thomas and Fermín Librado Tapia García. 2002. Amuzgo como lengua activa. In P. Levy (ed.), Del cora al maya yucateco: estudios lingüísticos sobre algunas lenguas indigenas mexicanas. Mexico City: UNAM.

Stewart, Cloyd \& Ruth Stewart. 2000. Diccionario amuzgo de San Pedro Amuzgos, Oaxaca. Mexico City: SIL Mexico.

Stump, Gregory. 2001. Inflectional morphology: A theory of paradigm structure. Cambridge: Cambridge University Press.

Tapia García, Fermín Librado. 1999. Diccionario amuzgo-español: el amuzgo de San Pedro Amuzgos. Mexico City: Plaza y Valdés.

Tapia García, Fermín Librado. n.d. Ndöba kondui jñ 'o na xén 'nkwi 'na nntz'a tz' $a^{n}$. Conjugación de verbos en amuzgos: amuzgo de San Pedro Amuzgos. Unpublished manuscript.

Williams, Cindy. 2005. An analysis of Amuzgo nominal tone. In R. Beam de Azcona \& M. Paster (eds.), Conference on Otomanguean and Other Oaxacan Languages, 147-161. Report 13 of the Survey of California and Other Indian Languages. Berkeley, CA: SCOIL. 